stream device (microstream capnography). The side-stream results were also compared to arterial or capillary $\mathrm{CO}_{2}$ $\left(\mathrm{PCO}_{2}\right)$ results. Respiratory disease severity was classified according to the ratio of dead space to tidal volume $(\mathrm{Vd} / \mathrm{Vt})$, which was calculated using the modified Bohr's equation. Agreement between the results of the mainstream and sidestream device were assessed by Bland-Altman analysis with linear regression and Spearman's rank correlation used to evaluate the strength of relationships. Ethical approval was given by the London (Camden \& King's Cross) Research Ethics Committee and parents gave informed written consent for their infants to take part in the study.

Results Fifty-four infants (28 male) were recruited with a median (IQR) gestational age of 31.6 (28.1-36.6) weeks and a birthweight of $1.43(0.91-2.66) \mathrm{kg}$. There was a strong correlation between the results of the mainstream and sidestream devices $(r=0.93 ; \mathrm{p}<0.001)$. The mean constant bias between the two methods of $\mathrm{EtCO}_{2}$ monitoring was $-0.49 \pm$ $0.43 \mathrm{kPa}(95 \%$ agreement levels -1.33 to $0.36 \mathrm{kPa})$. Side stream $\mathrm{EtCO}_{2}$ predicted $\mathrm{PCO}_{2}$ better in infants with less severe lung disease $\left(\mathrm{Vd} / \mathrm{Vt}<0.35, \mathrm{r}^{2}=0.72 ; \mathrm{p}<0.001\right)$ than in infants with more severe lung disease $\left(\mathrm{Vd} / \mathrm{Vt}>0.35, \mathrm{r}^{2}=0.35\right.$; $\mathrm{p}=0.002$ ).

Conclusion Side-stream capnography performed similarly to the gold standard mainstream capnography. The relationship of $\mathrm{EtCO}_{2}$ to arterial or capillary $\mathrm{CO}_{2}$ levels diverged with increasing respiratory disease severity, likely as a result of a higher physiological dead space and greater ventilation perfusion mismatch.

\section{G553 PREVALENCE AND PATTERN OF PRENATAL ALCOHOL EXPOSURE DETERMINED BY ALCOHOL BIOMARKERS IN NEWBORN BLOOD SPOT SCREENING CARDS}

EMA Henderson, H Mactier, D Favretto, D Young. Princess Royal Maternity, NHS Greater Glasgow and Clyde, Glasgow, UK

10.1136/archdischild-2020-rcpch.471

Fetal alcohol spectrum disorder (FASD) is the commonest preventable cause of preventable neurodisability but is under-diagnosed. Earlier diagnosis helps prevent secondary effects of FASD, resulting in better educational attainment and earlier healthcare interventions. Maternal self-report of prenatal alcohol exposure (PAE) is negligible, despite 1 in 7 women in Scotland drinking alcohol in pregnancy, as determined by alcohol biomarkers in meconium (Abernethy et al). Phosphatidylethanol (PEth), a direct metabolite of ethanol can be measured from newborn dried blood spot cards. In adults, PEth is $100 \%$ specific for alcohol exposure in blood samples for up to 12 days after a single drink. Blood spots cards are collected from almost all infants in the UK on day five and stored; retrospective testing might be possible when FASD is suspected.
Objective To investigate the potential utility of newborn blood spot cards for the detection of PAE to determine prevalence.

Population Total population of infants delivering in a single maternity hospital on each fourth day (random sample).

Methods 840 mother and infant dyads were recruited over an 11-month period to provide meconium and blood spot samples. The latter were collected coincident with routine newborn screening, when the original heel prick bleeding allowed. Maternal and infant demographics were collected via a health questionnaire. Samples were frozen and analysed at the University of Padova. The study had REC approval; all mothers gave written informed consent.

Results Blood spot cards were collected from 510 infants; 502 (98.5\%) were analysable for PEth. 216 (43.0\%) samples were positive for PEth and in 148 (29.5\%) the concentration was $>20 \mathrm{ng} / \mathrm{ml}$, indicative in adults of significant alcohol exposure. In the recruited cohort, $13.8 \%$ of mothers admitted to alcohol consumption beyond 20 weeks of pregnancy, $14.5 \%$ of meconium samples were positive for ethylglucuronide and $39.6 \%$ positive for fatty acid esters.

Conclusions Analysis of newborn blood screening cards for PEth is feasible. There is a need for further data correlating PEth values in the newborn with other biomarkers. Cut off values used for adults may overestimate PAE.

\section{G554 INTRA- AND INTER-OBSERVER VARIABILITY IN PDA SIZE MEASURED ON TRANSTHORACIC ECHOCARDIOGRAPHY (TTE) IN EXTREMELY PRETERM BABIES}

K Babla, R Dumitru, D Duffy, J Richards, A Kulkarni. Neonatal Unit, St George's Hospital NHS FT, London, UK

\subsection{6/archdischild-2020-rcpch.472}

Background The internal diameter of the patent ductus arteriosus (PDA) measured on transthoracic echocardiography (TTE) is commonly used in determining the need for treatment in clinical practice and enrolment in research trials. PDA size measured on TTE has not been well validated.

Objective To assess the intra- and inter-observer variability in PDA internal diameter measured on TTE on the same examination in babies born at $\leq 30$ weeks' gestation admitted to St George's neonatal unit.

Methods We included 56 babies born $\leq 30$ weeks' gestation that had a clinically indicated TTE. TTEs were performed by a single consultant neonatologist (AK) certified in echocardiography. PDAs were visualised using a high parasternal view, and cineloops were stored on DICOM Radiology viewing software without measurement annotations.

PDAs were measured at the narrowest diameter on 2Dimensional (2D) and Colour Doppler echocardiography

\begin{tabular}{|c|c|c|c|c|c|c|c|c|}
\hline & $\begin{array}{l}\text { Mean } \\
\text { Difference }\end{array}$ & $\begin{array}{l}\text { Max } \\
\text { Difference }\end{array}$ & $\begin{array}{l}\text { Min } \\
\text { Difference }\end{array}$ & Bias & $\begin{array}{l}\text { Upper Limit of } \\
\text { Agreement }\end{array}$ & $\begin{array}{l}\text { Lower Limit of } \\
\text { Agreement }\end{array}$ & $\begin{array}{l}\text { Repeatability } \\
\text { Coefficient }\end{array}$ & $\begin{array}{l}\text { Repeatability } \\
\text { Index }\end{array}$ \\
\hline $2 \mathrm{D}$ & 0.70 & 2.50 & 0.00 & -0.04 & 1.67 & -1.75 & 1.75 & $81 \%$ \\
\hline Colour & 0.96 & 2.50 & 0.00 & -0.83 & 0.63 & -2.30 & 1.49 & $62 \%$ \\
\hline
\end{tabular}

